\title{
Malignant phyllodes tumors display mesenchymal stem cell features and aldehyde dehydrogenase/ disialoganglioside identify their tumor stem cells
}

Jin-Jin Lin ${ }^{1,2}$, Chiun-Sheng Huang ${ }^{3}$, John Yu' ${ }^{1}$ Guo-Shiou Liao ${ }^{4}$, Huang-Chun Lien ${ }^{5}$, Jung-Tung Hung ${ }^{6}$, Ruey-Jen Lin ${ }^{6}$, Fen-Pi Chou ${ }^{2}$, Kun-Tu Yeh ${ }^{7^{*}}$ and Alice L Yu ${ }^{1,6^{*}}$

\begin{abstract}
Introduction: Although breast phyllodes tumors are rare, there is no effective therapy other than surgery. Little is known about their tumor biology. A malignant phyllodes tumor contains heterologous stromal elements, and can transform into rhabdomyosarcoma, liposarcoma and osteosarcoma. These versatile properties prompted us to explore their possible relationship to mesenchymal stem cells (MSCs) and to search for the presence of cancer stem cells (CSCs) in phyllodes tumors.

Methods: Paraffin sections of malignant phyllodes tumors were examined for various markers by immunohistochemical staining. Xenografts of human primary phyllodes tumors were established by injecting freshly isolated tumor cells into the mammary fat pad of non-obese diabetic-severe combined immunodeficient (NOD-SCID) mice. To search for CSCs, xenografted tumor cells were sorted into various subpopulations by flow cytometry and examined for their in vitro mammosphere forming capacity, in vivo tumorigenicity in NOD-SCID mice and their ability to undergo differentiation.

Results: Immunohistochemical analysis revealed the expression of the following 10 markers: CD44, CD29, CD106, CD166, CD105, CD90, disialoganglioside (GD2), CD117, Aldehyde dehydrogenase 1 (ALDH), and Oct-4, and 7 clinically relevant markers (CD10, CD34, p53, p63, Ki-67, Bcl-2, vimentin, and Globo H) in all 51 malignant phyllodes tumors examined, albeit to different extents. Four xenografts were successfully established from human primary phyllodes tumors. In vitro, $\mathrm{ALDH}^{+}$cells sorted from xenografts displayed approximately 10-fold greater mammosphere-forming capacity than $\mathrm{ALDH}^{-}$cells. GD2 ${ }^{+}$cells showed a 3.9-fold greater capacity than $\mathrm{GD2}^{-}$cells. $\mathrm{ALDH}^{+} / \mathrm{GD}^{+}$cells displayed 12.8 -fold greater mammosphere forming ability than $\mathrm{ALDH}^{-} / \mathrm{GD}^{-}$cells. In vivo, the tumor-initiating frequency of $\mathrm{ALDH}^{+} / \mathrm{GD}^{+}$cells were up to 33-fold higher than that of $\mathrm{ALDH}^{+}$cells, with as few as $50 \mathrm{ALDH}^{+} / \mathrm{GD}^{+}$cells being sufficient for engraftment. Moreover, we provided the first evidence for the induction of $\mathrm{ALDH}^{+} / \mathrm{GD}^{+}$cells to differentiate into neural cells of various lineages, along with the observation of neural differentiation in clinical specimens and xenografts of malignant phyllodes tumors. $\mathrm{ALDH}^{+}$or $\mathrm{ALDH}^{+} / \mathrm{GD2}^{+}$cells could also be induced to differentiate into adipocytes, osteocytes or chondrocytes.
\end{abstract}

Conclusions: Our findings revealed that malignant phyllodes tumors possessed many characteristics of MSC, and their CSCs were enriched in $\mathrm{ALDH}^{+}$and $\mathrm{ALDH}^{+} / \mathrm{GD}^{+}$subpopulations.

\footnotetext{
* Correspondence: 10159@cch.org.tw; ayu@gate.sinica.edu.tw

${ }^{7}$ Department of Surgical Pathology, Changhua Christian Hospital, Changhua

135, Nansiao St, Changhua 500, Taiwan

'Genomics Research Center, Academia Sinica, 128 Academia Road, Section 2,

Taipei 11529, Taiwan

Full list of author information is available at the end of the article
} 


\section{Introduction}

Breast phyllodes tumors (PTs) are rare neoplasms [1], representing less than $1 \%$ of all primary breast tumors in western countries [2]. However, an incidence rate of $6.92 \%$ was reported in a Singaporean study, suggesting its higher frequency among Asian women [3]. The World Health organization classified breast PTs into benign, borderline and malignant histopathologically [4]. However, there are occasional discrepancies between the clinical behavior and histopathological parameters of PTs, and the progression rate and outcomes of PTs remain unpredictable [1]. So far, there is no effective therapy other than surgery [5]. While all grades of breast PTs have the potential for local recurrence, only borderline and malignant PTs were shown to metastasize to other organs, such as lungs, bone and liver [6]. The metastatic PTs may show a resemblance to osteogenic sarcoma, chondrosarcoma, liposarcoma, leiomyosarcoma or rhabdomyosarcoma [7], which is attributed to the inherent heterogeneity within the primary PTs [1]. However, there has been no report of neural differentiation of malignant PTs. The versatile property of PTs to convert into various sarcoma types is reminiscent of the features of mesenchymal stem cells (MSCs). It has been well-documented that MSCs may differentiate into adipocytes, osteocytes and chondrocytes [8]. Subsequent studies demonstrated that MSCs can even be induced to neuron-like cells differentiation [9]. This led us to hypothesize that malignant PTs may possess MSC-like properties. Recently, GD2, a disialoganglioside has been identified as a marker for stem cells of MSCs [10] and breast cancer [11]. It will be of interest to determine whether GD2 is expressed in PTs and their stem cells.

Cancer stem cells (CSCs) have the capacity to create bulk tumors through self-renewal and differentiation [12]. A successful cancer therapy must thus eliminate these cells. The identification and isolation of CSCs thus become important in the treatment of malignant PTs. Although several markers have been successfully used to enrich cancer stem cells from various cancers, CSC markers for PTs have yet to be deciphered. In this study, we investigated the expression of a variety of markers in malignant PTs and searched for CSC markers for PTs.

\section{Methods}

\section{Clinical specimens of malignant PT}

All human breast cancer specimens were obtained from patients with malignant PT who had undergone initial surgery at the Tri-Service General Hospital (Taipei, Taiwan), National Taiwan University Hospital (Taipei, Taiwan), Chunghua Christian Hospital (Chunghua, Taiwan). Samples were fully encoded to protect patient confidentiality and were utilized under a protocol approved by the Institutional Review Board of Human Subjects Research Ethics Committees of Academia Sinica (Taipei, Taiwan) and collaborating medical centers. We have confirmed that informed written consent was obtained from those patients who provided fresh tumor specimens and that the IRB exempted the informed consent from patients who provided paraffin-embedded tissue sections.

\section{Animal model}

Female NOD-SCID (non-obese diabetic-severe combined immunodeficiency; Tzu Chi University, Hualien, Taiwan mice were purchased from Jackson Lab, Bar Harbor, ME, USA) and housed under specific pathogenfree conditions in the Animal Center of the Institute of Cellular and Organismic Biology of Sinica. We developed an orthotropic xenograft model as described by Kuperwasser et al. [13]. Briefly, fat pads were cleared and injected with a mixture of human primary cancer cells, human mammary stromal cells and Matrigel (BD $356237,2.5 \mathrm{mg} / \mathrm{ml}$, USA ${ }^{\circ}$. The human mammary stromal cells were obtained from patient BC515 who had undergone initial surgery. The tumor specimens were sliced to square $\left(1 \mathrm{~mm}^{2}\right)$ then subjected to enzymatic digestion by being incubated in RPMI1640 medium containing collagenase (Sigma C5138, 1,000 U/ml, USA), hyaluronidase (Sigma H3884, $300 \mathrm{U} / \mathrm{ml}$ ), and DNase I (Sigma DN25, $100 \mu \mathrm{g} / \mathrm{ml}$ ) at $37^{\circ} \mathrm{C}$ for one hour. After filtration through a $100-\mu \mathrm{m}$ cell strainer (BD Biosciences, USA), primary breast tumor cells were collected and resuspended in RPMI1640 medium supplemented with $5 \%$ FBS, and then injected into mammary fat pads of NOD-SCID mice. The animals were monitored weekly for tumor growth. Tumor cells from the xenografted mice were harvested in a similar manner and injected into other mice for serial passages. Mice were treated in accordance with the Institutional Animal Care and Use Committee of the Academia Sinica guidelines for experiments and approved by a committee of the same office.

\section{Immunohistochemical analysis}

Immunohistochemical analysis was performed on formalinfixed paraffin-embedded tissue. Sections $(3 \mu \mathrm{m})$ on coated slides were deparaffinized and rehydrated then subjected to antigen retrieval by autoclave or microwave in alkaline buffer pH9 (antigen Retrieval AR10, BioGenex, Fremont, CA, USA) for 10 minutes. After antigen retrieval, sections were treated with $\mathrm{H}_{2} \mathrm{O}_{2}$ to block the endogenous peroxidase activity. After washing out the $\mathrm{H}_{2} \mathrm{O}_{2}$, the sections were incubated with diluted primary antibodies as indicated by the manufacturer at room temperature for one hour, followed by staining with Super Sensitive Polymer-HRP Detection System (BioGenex), counter-staining with Mayer's hematoxylin and mounted in glycerin. The primary antibodies used included the following: CD44 (DF1485, DAKO, USA), CD29 (O.N.98, US Biological), CD106 (3H1814, US Biological), CD166 (MOG/ 
07, Novocastra, USA) CD105 (SN6h, DAKO), CD90 (3F102, US Biological), GD2 (14G2a, Bio Technetics, San Diego, CA 92121), ALDH1 (44/ALDH, it recognizes all ALDH1 isoforms, BD, USA), Oct-4 (240408, Santa Cruz, USA), CD117 (polyclonal c-Kit, DAKO), CD10 (56C6, BioCarta, USA), P53 (DO-7, DAKO), P63 (4A4, DAKO), Ki-67 (MIB-1, DAKO), bcl-2 Oncoprotein (124, DAKO), GloboH (MBr1, ALEXIS, USA), CD34 (QBEnd 10, DAKO), vimentin (Vim3B4, DAKO), collagen type II (polyclonal: 1 fibrillar collagen NC1 and 1VWFC, Abcam, UK), nestin (196908, R\&D and polyclonal, Santa Cruz Biotechnology, USA), $\beta$ III-tubulin (Tuj-1, R\&D and polyclonal, Millipore, USA) and glial fibrillary acidic protein (GFAP) (273807, $R \& D$ and polyclonal, Millipore). Sections were examined by pathologists.

\section{Immunofluorescent staining}

Cells were fixed in $4 \%$ paraformaldehyde at room temperature for 10 minutes. Primary antibodies were used at the dilutions suggested by the manufacturer. Cells were permeabilized with a permeabilization buffer (eBioscience) before staining with ALDH1, collagen type II, nestin, $\beta$ IIItubulin and GFAP. Secondary antibodies (1:100) labeled with Alisa488, Alisa594, PE or APC were added and incubated for one hour at room temperature. Nuclei were counterstained with 4',6-diamidino-2-phenylindole (DAPI). Stained mammospheres and monolayer cultured cells were imaged on a Confocal Microscope and Single Molecule detection system (Leica, TCS-SP5-MP-SMD).

\section{Cell sorting and analysis by flow cytometry}

Cell sorting and analysis by flow cytometry were performed as described previously [14]. Briefly, $1 \times 10^{5}$ single suspension cells prepared from xenograft tumor were incubated with a specific antibody on ice for 30 minutes. The mouse cells were stained with anti-H2Kd (BD Pharmingen $^{\mathrm{Ts}}$, 1:200) followed by PECy7-labeled secondary antibody (Jackson Labs, 1:250) on ice for 20 minutes. 7AAD-perCP5.5 (BD Biosciences, 1:100) was used to exclude the dead cells. An ALDEFLUOR assay kit (StemCell Technologies) was used to identify the cells with high ALDH activity as previously reported [15], which was treated with specific ALDH inhibitor, diethylaminobenzaldehyde (DEAB). BD FACS AriaTMIIU flow cytometer (Becton Dickinson) was used to sort the cells and FACSCanto (Becton Dickinson) was used to analysis the expression of indicated markers.

\section{Mammosphere assay}

To evaluate the potential of mammosphere formation from sorted cells, a density of $1 \times 10^{3}$ cells $/ \mathrm{ml}$ was plated in an ultra-low attachment 24-well plate (Corning, Acton, MA, USA) and cultured in Ham's F-12 serumfree medium (BioWhittaker) supplemented with BSA
(0.4\%), B27 (Invitrogen, Carlsbad, CA, USA), basic epidermal growth factor (bEGF) $(20 \mathrm{ng} / \mathrm{ml})$, hydrocortisone (1 $\mu \mathrm{M}$, Sigma) and epidermal growth factor $(20 \mathrm{ng} / \mathrm{ml}$, BD Biosciences, CA, USA). Twelve days after culture, the numbers of mammospheres were counted using an inverted microscope.

\section{Differentiation of human tumor stem cells}

Single suspension $\mathrm{ALDH}^{+}$or $\mathrm{ALDH}^{+} / \mathrm{GD}^{+}\left(3 \times 10^{5}\right)$ cells isolated from PTs (BC-P007, BC-P107 and BC-P515) were induced to differentiate into adipocytes with reagents, including dexamethasone (1 $\mu \mathrm{M}$, Sigma), insulin $(5 \mu \mathrm{g} / \mathrm{ml}$, Sigma), isobutylmethylxanthine $(0.5 \mathrm{mM}$, Sigma), and indomethacin (60 $\mu \mathrm{M}$, Sigma). The culture medium was refreshed once a week for 30 days. For the differentiation of osteocytes, cells were incubated with ascorbic acid $(50 \mu \mathrm{g} /$ $\mathrm{ml}$, Sigma), $\beta$-glycerophosphate (10 mM, Sigma), and dexamethasone $\left(10^{-7} \mathrm{M}\right.$, Sigma), and observed after 20 days. For the differentiation of chondrocytes, $1 \times 10^{5}$ cells were cultured in Dulbecco's modified Eagle's medium supplemented with Insulin-Transferrin-Selenium (ITS,50 mg/ml, GIBCO, USA), sodium pyruvate ( $1 \mathrm{mM}$, GIBCO), TGF- $\beta$ (10 ng/ml, Pepro Tech, Inc.) and dexamethasone $\left(10^{-7} \mathrm{M}\right.$, Sigma), and the chondrocytes were observed at Day 15. For neural stem cell, $\mathrm{ALDH}^{+} / \mathrm{GD}^{+}\left(5 \times 10^{3}\right)$ cells were cultured in Dulbecco's modified Eagle's medium supplemented with basic fibroblast growth factor (bFGF) ( $5 \mathrm{ng} / \mathrm{ml}$, Pepro Tech, USA), retinoic acid (0.5 $\mu \mathrm{M}$, Sigma) and 2-mercaptoethanol (1 mM) at Day 1; cyclic adenosine monophosphate (cAMP) (1 nM, Sigma) and ascorbic acid (100 $\mu \mathrm{M}$, Sigma) at Day 3; cAMP (1 nM, Sigma) and hydrocortisone (10 $\mu \mathrm{M}$, Sigma) at Day 5 ; nerve growth factor (NGF) (10 ng/ml, Sigma), epidermal growth factor (EGF) (1 mM, BD), butylated hydroxyanisole (200 $\mu \mathrm{M}$, Sigma) and ITS + premix (50 mg/ml, GIBCO) at Day 8 .

\section{Special stains}

The differentiated adipocytes were confirmed by Oil Red O staining as reported. Briefly, cells were fixed with $4 \%$ paraformaldehyde and then stained with Oil Red O $(0.3 \%$, Sigma) for 15 minutes at room temperature. Osteoblasts were confirmed by staining cells with Alizarin Red S $(0.5 \%$, Sigma) for 10 minutes at room temperature. For chondroblasts, Alcian blue staining was performed. Cells were stained with an Alcian blue $(\mathrm{pH}=2.5)$ kit (MUTO, Japan) for approximately 15 to 25 minutes at room temperature. After washing with acetic acid (3\%), Kernechtrot solution was used for a counter stain.

\section{Results}

\section{Successful engraftment of primary human PTs in} NOD-SCID mice

Using strategies developed by Dialynas et al. [16] and Yu (unpublished), fresh surgical specimens obtained from 
four patients with malignant PTs were successfully engrafted into NOD-SCID mice as illustrated in Figures 1A-D. For primary $\mathrm{BC} 007 \mathrm{PT}$ cells, the initial engrafted tumor was harvested on Day 184 after inoculation and serially propagated in NOD-SCID mice for up to nine generations. It was noted that the growth rate of the tumors accelerated with each passage, reaching $1 \mathrm{~cm}$ in diameter within 40 days at the ninth generation. Similarly, primary BC107, BC515 and BC877 PT cells were xenografted in NOD-SCID mice and harvested around Day 200. The histological features of four engrafted tumors, designated as BC-P007, BC-P107, BC-P515 and BC-P877 as examined by H\&E staining were very similar to their primary counterparts (Figure 1).

\section{Phenotypic markers of primary PTs and xenografts}

Paraffin blocks from 47 individual patients, four fresh specimens of malignant PT and their xenografted tumors, were examined by immunohistochemical staining for the following markers: CD44 (HCAM), CD29 (integrin $\beta-1$ ), CD106 (VCAM-1), CD166 (ALCAM), CD105 (Endoglin), CD90 (Thy-1) [17-20], GD2 (ganglioside) [11], CD117 (c-kit receptor) [21], ALDH1 [15], embryonic stem cell marker Oct-4 (Octamer-4 in abbreviation), CD34 [22], CD10, p53, p63, Ki-67, Bcl-2 [23] and vimentin [24]. Mesenchymal progenitor cell-line HS-5 was chosen as a control. We found that all markers were detectable in the 51 malignant PT specimens with the following

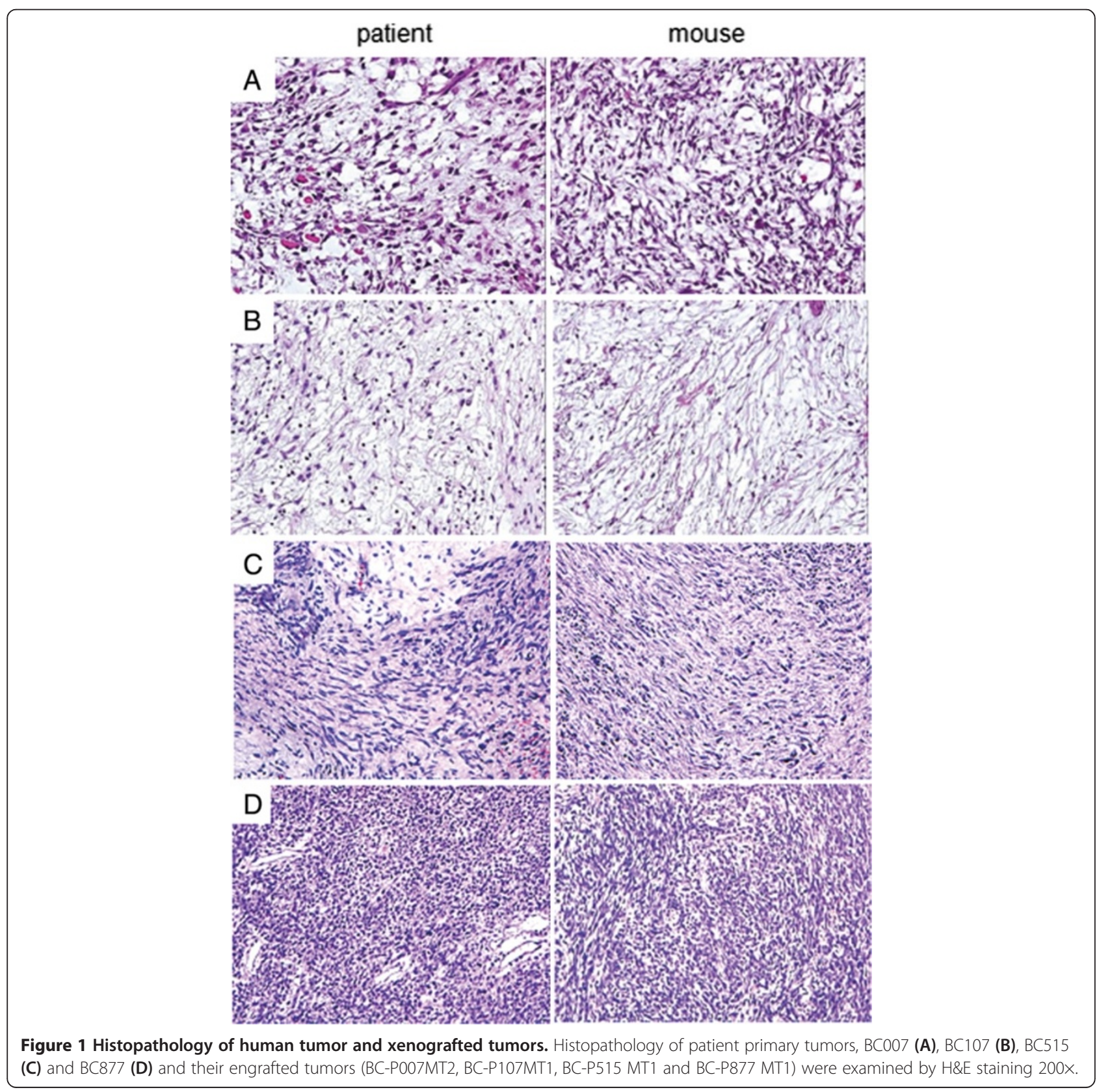


frequencies among different patients: GD2 (100\%, 51/51) CD166 (78.4\%，40/51), CD90 (78.4\%, 40/51), CD44 (68.6\%, 35/51), CD106 (29.4\%, 15/51), CD29 (27.4\%, $14 / 51)$ and CD105 (1.9\%, 1/51) (Table 1). Vimentin was expressed in all tumor specimens, consistent with their mesenchymal lineage [25]. CD117 was expressed in $70.5 \%$ of the malignant PT specimens which is in line with the report of its expression in 13\% and 67\%, of benign and malignant PTs, respectively [26]. Ki-67, a marker for cell proliferation, was expressed in $82.3 \%$ of the malignant PT specimens. CD10 was detected in $60.7 \%$ (positive: $\geq 10 \%$ ) [4] of the malignant PT specimens, which is consistent with the previous report of its presence in four of six malignant PTs but negative in all benign ones [4]. Overexpression of p53 was noted in $50.9 \%$ of the malignant PT specimens, including four fresh tumors as well as their xenografted tumors. Interestingly, the expression of p63, a member of the $p 53$ gene family highly expressed in the basal or progenitor layers of many epithelial tissues, was observed in 9.8\% of the malignant PT specimens. $\mathrm{Bcl}-2$ expression was found in $37.2 \%$ of the malignant PT specimens, but not in the four fresh primary tumors and their xenografted tumors. CD34, a transmembrane glycoprotein expressed on hematopoietic stem and progenitor cells, endothelial cells, bone marrow progenitor cells, and many mesenchymal tumor cells [27], was detected in $52.9 \%$ of the malignant PT specimens. Globo H, a hexasaccharide antigen commonly found in breast carcinoma (61 to 80\%) [14,28], was noted in $9.8 \%$ of the malignant PT specimens. As summarized in Table 1, results from the immunohistochemical analysis showed that malignant PTs possess MSC-like properties and that the four fresh malignant PT samples and their corresponding xenografts showed largely similar immunohistochemical profiles as their parent tumors, up to the eighth passage (Additional file 1: Table S1). Consistent with their origin from stromal cells, these four primary malignant PTs, their non-tumor part, and their xenografts all lacked cytokeratins, but expressed vimentin except non-tumor parts of patient BC515 (Additional file 1: Table S2). In addition, we examined the phenotypes of nontumor part (515NT and $877 \mathrm{NT}$ ) by immunohistochemical

Table 1 Expression of various markers in PTs obtained from patients or patient-derived xenografts

\begin{tabular}{|c|c|c|c|c|c|c|c|}
\hline & & $\begin{array}{l}\% \text { positive cases }(n=51) \\
\text { (\% positive cells) }\end{array}$ & $\begin{array}{l}\text { BC007/ } \\
\text { BC-P007MT1 }\end{array}$ & $\begin{array}{l}\text { BC107/ } \\
\text { BC-P107MT1 }\end{array}$ & $\begin{array}{l}\text { BC515/ } \\
\text { BC-P515MT1 }\end{array}$ & $\begin{array}{l}\text { BC877/ } \\
\text { BC-P877MT1 }\end{array}$ & HS-5 \\
\hline \multirow[t]{9}{*}{ MSC marker } & CD44 & $68.6 \%$ & $50 / 60$ & $60 / 30$ & $-/-$ & $-/-$ & + \\
\hline & CD29 & $27.4 \%$ & $10 / 40$ & $<5 / 30$ & $5 /<1$ & $-/-$ & + \\
\hline & CD166 & $78.4 \%$ & $<5 /<5$ & $10 / 50$ & $5 / 5$ & $90 / 90$ & + \\
\hline & CDI06 & $29.4 \%$ & $30 /<10$ & $<10 /<10$ & $-1-$ & $80 / 80$ & + \\
\hline & CD105 & $1.9 \%$ & $-/-$ & $-/-$ & $-1-$ & $50 / 90$ & + \\
\hline & CD90 & $78.4 \%$ & $<10 /<10$ & $10 / 10$ & $55 / 75$ & $<5 / 70$ & + \\
\hline & CD117 & $70.5 \%$ & $-/ 20$ & $-/-$ & $5 / 50$ & $80 / 95$ & + \\
\hline & GD2 & $100 \%$ & $80 / 50$ & $75 / 30$ & $90 / 75$ & $60 / 30$ & + \\
\hline & & $(<10$ to $>90)$ & & & & & \\
\hline \multirow[t]{3}{*}{ Stem cell marker } & $\mathrm{ALDH}$ & $100 \%$ & $20 / 1$ & $3-5 /<1$ & $40 / 5$ & $<1 /<5$ & + \\
\hline & & $(<10$ to $>90)$ & & & & & \\
\hline & Oct-4 & $47.0 \%$ & $10 / 5$ & $30 / 10$ & $<1 / 35$ & $<5 /<5$ & + \\
\hline \multirow{9}{*}{$\begin{array}{l}\text { PT clinically relevant } \\
\text { markers }\end{array}$} & Vimentin & $100 \%$ & $90 />90$ & $90 />70$ & $80 / 20$ & $>95 />95$ & + \\
\hline & & $(<10-$ to $>90)$ & & & & & \\
\hline & Ki-67 & $82.3 \%$ & $40 / 40$ & $10 / 20$ & $5 /<3$ & $65 />95$ & + \\
\hline & CD10 & $60.7 \%$ & $20 / 5$ & $10 / 70$ & $5 / 5$ & $<10 / 30$ & + \\
\hline & CD34 & $52.9 \%$ & $-/-$ & $40 / 70$ & $80 / 20$ & $-/-$ & - \\
\hline & p53 & $50.9 \%$ & $<10 /<10$ & $<5 / 10$ & $70 / 60$ & $>95 />95$ & + \\
\hline & $\mathrm{BCl}-2$ & $37.2 \%$ & $-/-$ & $-/-$ & $-/-$ & $-/-$ & - \\
\hline & p63 & $9.8 \%$ & $60 / 10$ & $-/-$ & $-/-$ & $-/-$ & - \\
\hline & Globo-H & $9.8 \%$ & $-/-$ & $-/-$ & $-1-$ & $80 / 80$ & - \\
\hline
\end{tabular}

Fifty-one malignant PTs were tested by immunohistochemical staining for a panel of 18 markers. The expression level of each marker was scored based on the positive percentage by stained cells by clinical pathologists. The percentage of all 51 cases expressing each marker is listed in the third row. The xenografted tumors in NO-SCID mice (BC-P007MT1, BC-P107 MT1, BC-P515 MT1 and BC-P877 MT1) showed a similar immunohistochemical staining profile for most markers as did the parental tumors (BC007, BC107, BC515 and BC877). All markers were expressed in malignant PTs. HS-5 (human marrow stromal cell lines) as the control in this table, the expression level of each marker was classified into two categories, negative (-) and positive (+), by clinical pathologists. 
analysis and showed that their phenotypes were mostly different from their original tumors and xenografts (Additional file 1: Table S1).

\section{$\mathrm{ALDH}^{+}$identifies cancer stem cells in malignant PTs}

ALDH has been shown to enrich breast stem/progenitor cells [29]. We thus examined the expression of ALDH in malignant PTs. As shown in Figure 2A, a small fraction $(7.6 \%)$ of the xenografted tumor cells from BC-P007 was found to be positive for ALDH activities as determined by an ALDEFLUOR assay. The percent of cells with high ALDH activity in four xenografted tumors ranged from 3 to $30 \%$. Several lines of evidence indicated that $\mathrm{ALDH}^{+}$cells displayed features of tumor stem cells. First, the sorted $\mathrm{ALDH}^{+}$cells spontaneously formed colonies adherent to the monolayer culture dish (Figure 2B). This phenomenon was observed in the monolayer cultures derived from all four xenografts. The colony forming efficiencies for BC-P007 and BC-P515 were approximately 14.1 to $16.6 / 10^{6}$ and approximately 15.5 to $17.5 / 10^{6}$, respectively, while those for $\mathrm{ALDH}^{-}$cells were only approximately 0.8 to $1.6 / 10^{6}$ and approximately 0.11 to $0.23 / 10^{6}$, respectively (Additional file 1 : Table S3). Upon trypsinization and replating, the colony formation persisted through serial passages for 20 passages, but the number of colonies declined gradually with each passage, along with a reduced growth rate. On the other hand, the $\mathrm{ALDH}^{-}$cell population lasted for one or two passages in monolayer culture only with occasional colony formation.

Secondly, ALDH ${ }^{+}$cells sorted from BC-P007, BC-P107 and $\mathrm{BCP}-515$ were able to generate mammospheres which could be propagated for at least 10 passages (Figure 2C). The average mammosphere forming efficiency (MFE) of $\mathrm{ALDH}^{+}$cells from BC-P007, BC-P107 and BC-P515 was $19 \pm 2.0 / 1,000$ cells as compared to $1.9 \pm 0.5 / 1,000$ cells for $\mathrm{ALDH}^{-}$cells $(P<0.0001)$ (Figure 3D). Using limiting dilution of $\mathrm{ALDH}^{+} \mathrm{BC}$-P515 cells at one cell/well, we observed that a single cell could give rise to mammosphere formation, supporting its clonal origin (Additional file 1: Table S4). Curiously, MFE was much higher in the single cell experiments (approximately 7.1 to $11.8 \%$ ) than in the bulk experiments (2.8\%). This suggested that clumping of cells when seeded in bulk might have accounted for their lower MFE. Immunofluorescence analysis of colonies in monolayer culture or mammopheres revealed high expression of the following markers: CD29, CD44 and CD166. Interestingly, CD44 appeared to concentrate at the colony periphery, while CD10, CD29 and CD166 localized in the center of the colony (Additional file 1: Figure S1A-C and E-G). ALDH (antibody) positive cells also congregated at the colony or mammosphere periphery (Additional file 1: Figure S1D-H).

Lastly, the in vivo tumorigenicity of $\mathrm{ALDH}^{+}$and $\mathrm{ALDH}^{-}$ cells sorted from BC-P007 and BC-P515 xenograft were examined in NOD-SCID mice. The tumor formation frequency for $\mathrm{ALDH}^{+}$cells $\left(1\right.$ in $\left.2 \times 10^{4}\right)$ from both xenografts was estimated to be 5 - and 21-fold that of $\mathrm{ALDH}^{-}$cells ( 1 in $1.1 \times 10^{5}$ and 1 in $>4.2 \times 10^{5}$ ) for BC-P007 and BC-P515, respectively, as shown in Table 2. Interestingly, $\mathrm{ALDH}^{+}$cells from monolayer cultures and mammospheres derived from BC-P007 xenografts were even more tumorigenic than $\mathrm{ALDH}^{+}$cells freshly sorted from xenografts (Additional file 1: Table S5). As few as $50 \mathrm{ALDH}^{+}$cells from mammospheres or monolayer cultures were sufficient for tumor engraftment (Figure 2D). The frequencies of tumor formation for cultured $\mathrm{ALDH}^{+}$cells ( 1 in 53 for monolayers, 1 in 1 for mammospheres) were significantly higher than that of $\mathrm{ALDH}^{+}$cells sorted from BC-007 xenografts without culture $(P<0.001 ; P<0.001$, respectively; Additional file 1 : Table S5) but there was no significant difference between the monolayer- and mammosphere-derived $\mathrm{ALDH}^{+}$cells $(P=0.3)$. On the other hand, the tumor formation frequency of $\mathrm{ALDH}^{-}$cells derived from monolayers were significantly lower than that of ALDH + cells ( 1 in $1.8 \times$ $10^{5}$ vs. 1 in 53, $P<0.001$; Additional file 1: Table S5). Collectively, these findings suggest that $\mathrm{ALDH}^{+}$cells sorted from BC-P007 and BC-P515 xenografts, were enriched in PT stem cells, which were further enriched by in vitro cultures as monolayers or mammospheres.

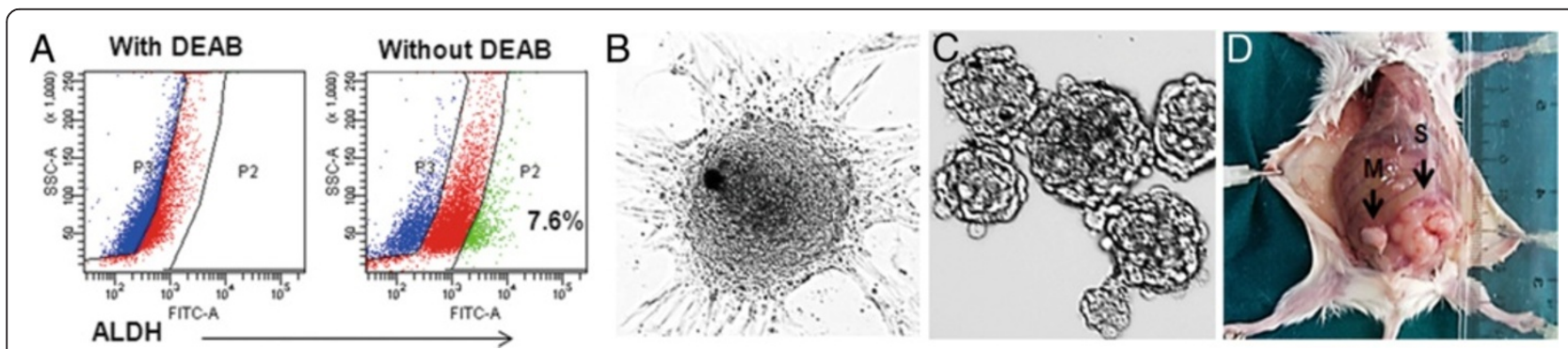

Figure 2 Features of $\mathrm{ALDH}^{+}$cell population in monolayer and mammosphere culture. (A) Flow cytometry revealed $7.6 \%$ of the xenografted tumor cells in BC-P007MT3 (passage 3) were positive for ALDEFLUOR assay. (B) The ALDEFLUOR-positive cells were incubated in a culture dish, and formed colonies spontaneously (200X). (C) BC-P007 ALDH ${ }^{+}$cell are capable of generating mammospheres in culture (200X). (D) As few as $50 \mathrm{ALDH}^{+}$harvested from mammospheres (S) or monolayer (M) were sufficient for tumor engraftment. ALDH, Aldehyde dehydrogenase 1. 


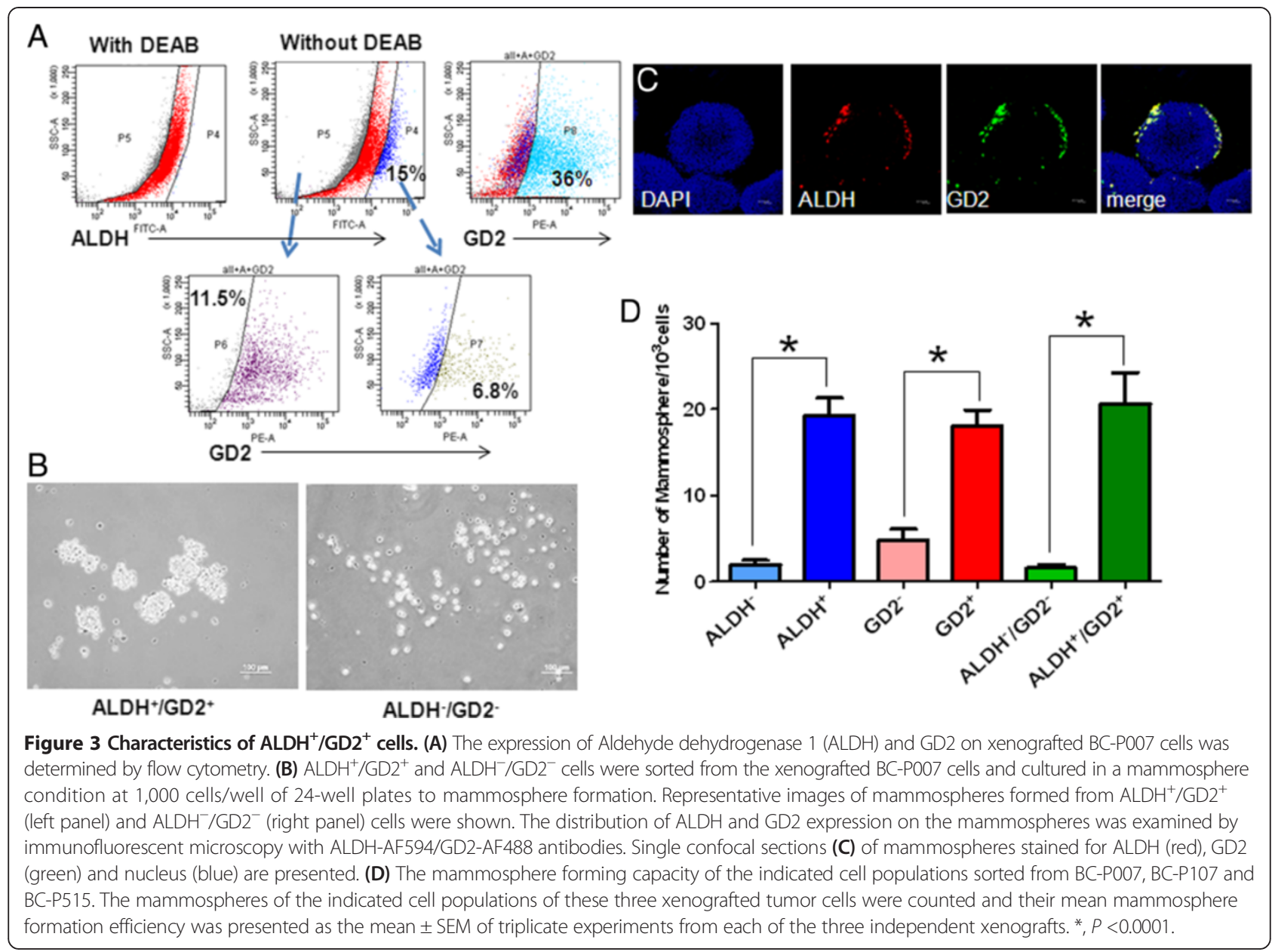

Table 2 Engraftment capacity of different cell populations sorted from cryopreserved tumor cells

\begin{tabular}{|c|c|c|c|c|c|c|c|c|c|c|c|c|}
\hline BC-P007 & $4 \times 10^{4}$ & $2 \times 10^{4}$ & $1 \times 10^{4}$ & $5 \times 10^{3}$ & $4 \times 10^{3}$ & $1 \times 10^{3}$ & 500 & 100 & 50 & 20 & Frequency $^{\bar{\top}}$ & Distribution $^{\#}$ \\
\hline$\overline{\mathrm{ALDH}^{+}}$ & & $3 / 8$ & & & $3 / 8$ & $1 / 3$ & $1 / 7$ & & & & $1: 2.0 \times 10^{4}$ & $75 \%$ \\
\hline $\mathrm{ALDH}^{-}$ & & $0 / 4$ & & & $0 / 6$ & $1 / 7$ & $0 / 3$ & $0 / 4$ & & & $1: 1.1 \times 10^{5}$ & $25 \%$ \\
\hline $\mathrm{ALDH}^{+} / \mathrm{GD}^{+}$ & & $2 / 2$ & & & $3 / 3$ & $6 / 10$ & & $5 / 10$ & $2 / 20$ & $0 / 3$ & $1: 6.1 \times 10^{2}$ & \\
\hline $\mathrm{ALDH}^{-} / \mathrm{GD}^{-}$ & $0 / 4$ & & $0 / 1$ & $0 / 8$ & $2 / 10$ & $0 / 15$ & & & & & $1: 1.3 \times 10^{5}$ & \\
\hline $\mathrm{ALDH}^{+}$ & & $3 / 8$ & & & $3 / 8$ & $1 / 3$ & $1 / 7$ & & & & $1: 2.0 \times 10^{4}$ & \\
\hline $\mathrm{ALDH}^{+} / \mathrm{GD}^{+}$ & & $2 / 2$ & & & $3 / 3$ & $6 / 10$ & & $5 / 10$ & $2 / 20$ & $0 / 3$ & $1: 6.1 \times 10^{2}$ & \\
\hline BC-P515 & $1 \times 10^{5}$ & $2 \times 10^{4}$ & $1 \times 10^{4}$ & & $4 \times 10^{3}$ & $1 \times 10^{3}$ & 500 & 100 & & 50 & Frequency $^{\bar{\top}}$ & Distribution $^{\#}$ \\
\hline $\mathrm{ALDH}^{+}$ & & $1 / 4$ & $0 / 3$ & & $1 / 4$ & $3 / 9$ & & $1 / 5$ & & & $1: 2.0 \times 10^{4}$ & $96 \%$ \\
\hline $\mathrm{ALDH}^{-}$ & & $0 / 4$ & $0 / 3$ & & $0 / 2$ & $0 / 9$ & & & & & $1:>4.2 \times 10^{5}$ & $4 \%$ \\
\hline $\mathrm{ALDH}^{+} / \mathrm{GD}^{+}$ & & $1 / 3^{*}$ & $7 / 10$ & & & $4 / 5$ & $0 / 1$ & $2 / 7$ & & $1 / 2$ & $1: 7.1 \times 10^{3}$ & \\
\hline $\mathrm{ALDH}^{-} / \mathrm{GD}^{-}$ & $0 / 1$ & $0 / 2$ & $1 / 9$ & & $0 / 4$ & $0 / 10$ & & & & & $1: 2.5 \times 10^{5}$ & \\
\hline $\mathrm{ALDH}^{+}$ & & $1 / 4$ & $0 / 3$ & & $1 / 4$ & $3 / 9$ & & $1 / 5$ & & & $1: 2.0 \times 10^{4}$ & \\
\hline $\mathrm{ALDH}^{+} / \mathrm{GD}^{+}$ & & $1 / 3$ & $7 / 10$ & & & $4 / 5$ & $0 / 1$ & $2 / 7$ & & $1 / 2$ & $1: 7.1 \times 10^{3}$ & \\
\hline
\end{tabular}

BC-P007 and BC-P515 cryopreserved tumor cells from patient-derived xenografts of PT were sorted by FACS into ALDEFLUOR-positive, ALDEFLUOR-negative or ALDEFLUOR and GD2 double positive and double negative cells. Varying numbers of the sorted cells were injected in fat pads of NOD-SDID mice to evaluate their tumor-initiating potential. The frequency of cancer-initiating cells was analyzed using ELDA software.

*:Including one of three mice died the day after tumor injection.

\#:The distribution of tumor-initiating cells among the BC-P007 and BC-P515 ALDH + and ALDH-cells.

$\bar{T}$ :Frequency was calculated by ELDA software, although the $P$-value for likelihood ratio test of single-hit model in each group was less than $P=0.5$. 


\section{Comparison of primary cultures of cells derived from the tumor and non-tumor part of PT}

To address the possibility that the mammmospheres may be derived from $\mathrm{ALDH}^{+}$normal stromal cells, we established primary cultures of cells derived from the tumor part and non-tumor part of human breast cancer sample BC515. The primary culture of the non-tumor part (515-NT) could be propagated for up to approximately 18 to 19 passages only, whereas the tumor part can be sustained in vitro for at least 35 passages. The tumorigenic ability of $515 \mathrm{NT}$ was tested by injecting $2.5 \times 10^{6}$ cells of $515 \mathrm{NT}$ into the cleared fat pads of 12 mice. None of these mice showed tumor growth up to Day 291. On the other hand, injection of $1 \times 10^{6}$ cells of BC-P515 yielded tumor growth in 20/20 mice by Day 7 after injection. In addition, the $\mathrm{ALDH}^{+}$and $\mathrm{ALDH}^{-}$cells of BC-P515 and 515NT were sorted to evaluate their ability for mammosphere formation. As shown in Additional file 1: Table S6, the number of mammospheres was at least one log higher (10-fold) in $\mathrm{ALDH}^{+}$BC-P515 cells than in $\mathrm{ALDH}^{+} 515$ NT cells. Furthermore, BCP515 contained 40 XO chromosomes with several karyotypic abnomalities, in contrast to a normal karyotype with $46 \mathrm{XX}$ in $515 \mathrm{NT}$ (data not shown).

\section{$\mathrm{ALDH}^{+} / \mathrm{GD2}^{+}$cells could serve as a marker for cancer stem cells in malignant PTs}

To screen for other markers of cancer stem cells in PTs, we harvested the BC-P007 xenografted tumor cells for FACS sorting using a panel of markers including CD29, CD44, CD90, CD117, CD 133, CD166, GD2, CD10, CD24 and ALDH. Following cell sorting, various subpopulations of the BC-P007 xenografted tumor were evaluated for their ability to grow as monolayer cultures with serial passages. CD24 and CD133 were not expressed in BC-P007 and subpopulations sorted by CD10, CD90, CD117 and CD166 grew very poorly in monolayer cultures. $\mathrm{CD} 29^{+}$and $\mathrm{CD} 44^{+}$cells lasted for two to three passages only. The neural ganglioside GD2 was reported to be a marker for MSC and GD2-positive MSC could be induced to differentiate into osteoblasts, adipocytes and chondroblasts [10]. In addition, GD2 expression was observed in $25 \%$ to $67 \%$ of the cells from four xenografted tumors. Thus, GD2 was also included in the panel for testing. Notably, GD2 ${ }^{+}$cells propagated for more than 18 generations whereas $\mathrm{GD}^{-}$cells did not last for more than three passages. Furthermore, $\mathrm{ALDH}^{+} / \mathrm{GD}^{+}$(6.8\%) and $\mathrm{ALDH}^{-} / \mathrm{GD}^{-}$cells (11.5\%) were sorted from BC-P007 xenograft (Figure 3A), and cultured in mammosphere condition. As shown in Figure $3 \mathrm{~B}, \mathrm{ALDH}^{+} / \mathrm{GD}^{+}$cells formed significantly more mammospheres than double negative cells. Immunofluorescence staining showed the preferential localization of $\mathrm{ALDH}^{+} / \mathrm{GD2}^{+}$cells at the sphere periphery (Figure 3C, Z- stack). Next, we compared the mammosphere forming capacities for each subpopulation of BC-P007, BC-P107 and BC-P515 xenografts based on their ALDH and GD2 expression. As shown in Figure 3D, MFE of GD2 positive cells from these three xenografts was $18.08 \pm 1.7 / 1,000$ cells, as compared to $4.8 \pm 1.2$ for GD2 negative cells $(P<0.0001)$, and MFE of $\mathrm{ALDH}^{+} / \mathrm{GD}^{+}$cells was $20.5 \pm$ $3.6 / 1,000$ as compared to $1.6 \pm 0.4$ for $\mathrm{ALDH}^{-} / \mathrm{GD}^{-}$cells $(P<0.0001)$. These results suggested that ALDH/GD2 single and double positive cells might have greater tumorigenic potentials than single and double negative cells. As a further proof, cryopreserved BC-P007 and BC-P515 xenografted cells were sorted into single or double positive and double negative cells for ALDH and GD2 and injected into NOD-SCID mice. Significantly, the tumor-initiating frequency of $\mathrm{ALDH}^{+} / \mathrm{GD}^{+}$cells sorted from cryopreserved BC-P007 and BC-P515 was estimated to be approximately 35.2 - to 1,000 - and approximately 2.8 - to 33.3-fold higher than $\mathrm{ALDH}^{-} / \mathrm{GD}^{-}$and $\mathrm{ALDH}^{+}$cells, respectively (Table 2 ). In addition, the phenotypic profile of xenograted tumors derived from $\mathrm{ALDH}^{+} / \mathrm{GD}^{+}$cells showed intratumor heterogeneity, similar to the parental tumors, and the sorted $\mathrm{ALDH}^{+} / \mathrm{GD}^{+}$cells could be serially passaged in mice for more than three generations (Additional file 1: Table S7).These findings support the notion that $\mathrm{ALDH}^{+} / \mathrm{GD}^{+}$expression could serve as a marker to enrich cancer initiating cells in malignant PTs.

\section{In vitro differentiation of $\mathrm{ALDH}^{+} / \mathrm{GD}^{+}$cells into neuro-ectodermal cell lineages}

We next evaluated the potentials of ALDH/GD2 single positive and double positive cells from BC-P007, BCP107 and BC-P515 xenografted tumors to differentiate into various cell lineages. Using an in vitro culture system, we found that the $\mathrm{ALDH}^{+}$cells sorted from BCP007 xenografted tumors could be induced to differentiate into adipocyte as revealed by Oil Red $\mathrm{O}$ staining (Figure 4A), osteocytes with positive staining by Alizarin red (Figure 4B), and chondrocytes, with immunofluorescent staining for collagen type II (Figure 4C). Furthermore, GD2 and collagen type II were expressed by different populations of cells in cultures induced for chondrocyte differentiation (Figure 4D, E). When $\mathrm{ALDH}^{+} / \mathrm{GD}^{+}$ cells were induced for neuronal differentiation with retinoic acid, hydrocortisone, ITS and cAMP, spindle-shaped cells emerged on Day 7 (Figure 4F), which displayed a network architecture by Day 14 (Figure 4G). By Day 22, these cells differentiated into different neural lineages, as identified by specific neural markers, including nestin (neuron stem/ progenitors cell marker), $\beta$ III-tubulin (immature neuronal progenitor cell marker) and GFAP (glial fibrillary acidic protein, marker for astrocytes) (Figure 4H). Interestingly, cells staining for nestin in the cell body and BIII-tubulin in the tail portion were noted 


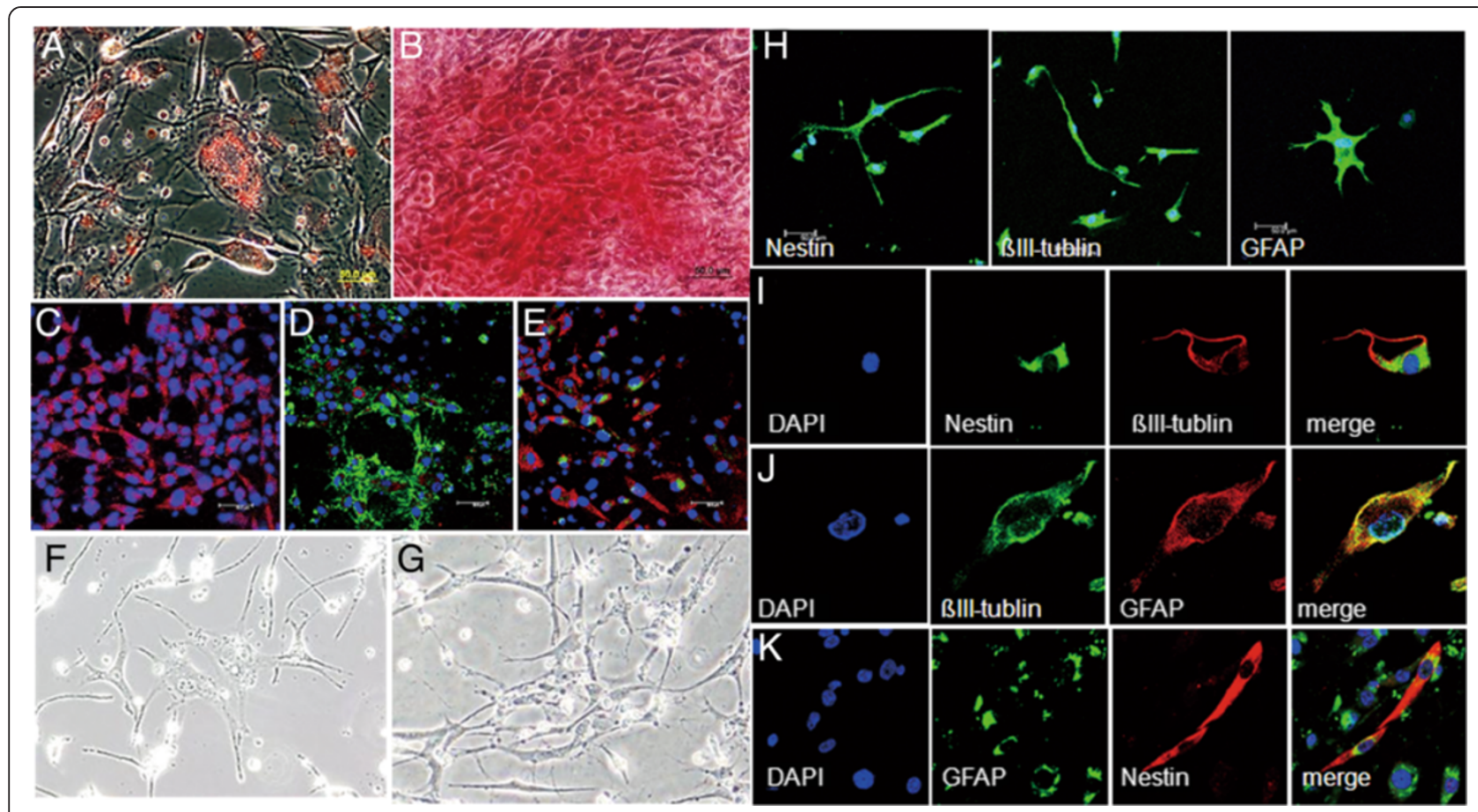

Figure 4 In vitro differentiation of $\mathrm{ALDH}^{+} / \mathrm{GD2}^{+}$cells into neuro-ectodermal lineages. Monolayer cultures of Aldehyde dehydrogenase 1 $(\mathrm{ALDH})^{+}$cells obtained from BC-P007 xenografts were induced to differentiate into various cells lineages. Adipocyte was induced by incubation with dexamethasone, insulin, isobutylmethylxanthine and indomethacin for 30 days, and identified by Oil Red O staining (A. 400x). Osteocytes were induced by treatment with ascorbic acid, $\beta$-glycerophosphate and dexamethasone for 23 days and examined by Alizarin red staining (B. 400X). Chondrocytes were induced by culturing with ITS + premix, sodium pyruvate, TGF- $\beta$ and dexamethasone for 15 days, and confirmed by immunofluorescence staining with anti-human collagen II antibody (C. 400X). The expression of GD2 (green) and collagen type 2 (red) in chondrocytes was detected by fluorescence-conjugated antibodies and observed under fluorescence microscope (D and E. 400X). Neuron-like cells were induced by incubation of the $\mathrm{ALDH}^{+} / \mathrm{GD} 2^{+}$cells from xenografted tumor of BC-P007 with retinoic acid, hydrocortisone, ITS and c-AMP, and was observed under phase contrast microscope on Day 7 (F. 400x) and Day 14 (G. 400x). Twenty-two days after culture, the neuronal lineages of these cells were examined by fluorescence microscopy with AF488 labeled antibodies against nestin, Blll-tubulin and GFAP (H. 400X). And, double staining of nestin and BIII-tubulin, BIII-tubulin and GFAP and GFAP and nestin (I-K, 1,000X) with AF488 or AF594-labeled antibodies was shown.

occasionally (Figure 4I). In addition, a few cells displayed co-localized staining for GFAP and BIII-tubulin (Figure 4J). On the other hand, nestin and GFAP expression was observed in separate cell populations (Figure 4K). These findings demonstrated the ability of $\mathrm{ALDH}^{+} / \mathrm{GD}^{+}$cells to differentiate into diverse lineages of neural cells. Furthermore, the $\mathrm{ALDH}^{+} / \mathrm{GD}^{+}$cells could also be induced to differentiate into adipocytes, osteocytes and chondrocytes, comparable to $\mathrm{ALDH}^{+}$cells. Similar results were observed with $\mathrm{ALDH}^{+}$or $\mathrm{ALDH}^{+} / \mathrm{GD2}^{+}$cells sorted from the BCP107 and BC-P515 xenografted tumors (data not shown). Our findings suggest that $\mathrm{ALDH}^{+} / \mathrm{GD}^{+}$possess the ability to differentiate along various cell lineages, including neuro-ectodermal lineages. This is the first documentation for neural differentiation of malignant $\mathrm{PT}$ in vitro.

\section{Capacity of $\mathrm{ALDH}^{+}$or $\mathrm{ALDH}^{+} / \mathrm{GD2}^{+}$cells to undergo spontaneous differentiation in vivo}

Among more than 16 BC-P007 xenografted mice, onefifth showed metastatic lesions, mostly in the thoracic cavity. Some of the metastatic tumors contained cells with lacunar space easily discernible by $H \& E$ staining, reminiscent of chondroid cells (Figure 5A), which were confirmed by Alcian blue staining (Figure 5B) and immunohistochemical staining with anti-human collagen type II antibody (Figure 5C). Other lesions differentiated into different lineages of neural cells with the expression of nestin, BIII-tubulin and GFAP by immunohistochemical staining (Figure 5D). Interestingly, the primary tumor of BC-P007 xenograft at the site of injection expressed collagen type II $(50 \%$ moderate staining, data not shown), but not nestin, BIII-tublin and GFAP. These findings suggested that mammospheres derived from $\mathrm{ALDH}^{+}$cells possessed the ability to differentiate into various cell lineages in vivo. Similarly, mammospheres derived from $\mathrm{ALDH}^{+} / \mathrm{GD}^{+}$cells could form xenograft tumors with prominent features of neural and chondroid differentiation. Figure 5E showed an interesting tumor engrafted from $\mathrm{ALDH}^{+} / \mathrm{GD}^{+}$cells with a distinct dichotomy in differentiation. The right portion of the tumor 


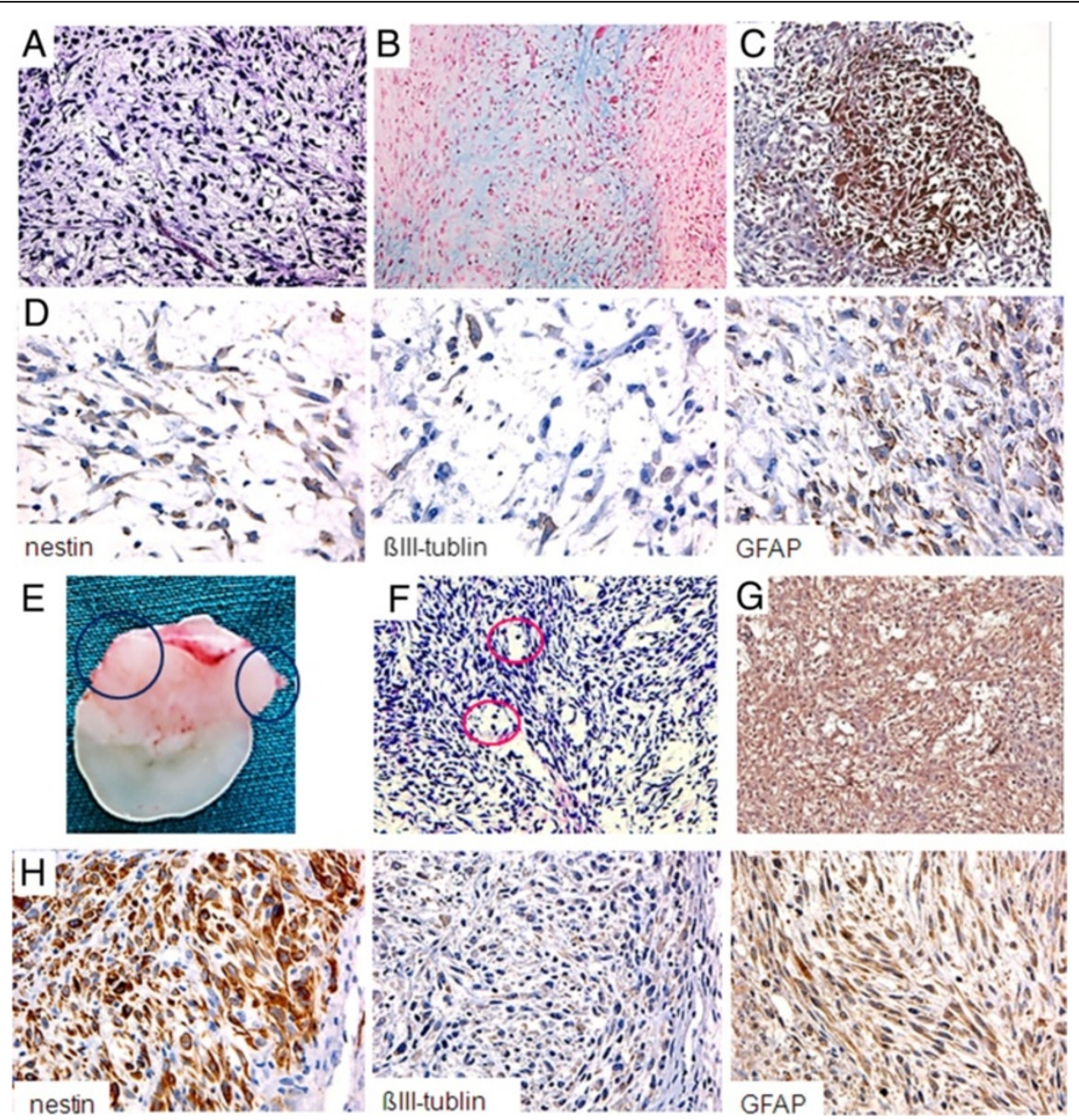

Figure 5 Capacity of $\mathrm{ALDH}^{+}$and $\mathrm{ALDH}^{+} / \mathrm{GD}^{+}$cells to undergo differentiation in vivo. Mammospheres derived from BC-P007 Aldehyde dehydrogenase $1(\mathrm{ALDH})^{+}$cells were engrafted. Five thousand $\mathrm{ALDH}^{+}$cells were injection into fat pads and on Day 86, severe tumor nodules were observed in the thoracic cavity. In addition to tumor at the injection site, one of the metastatic tumors removed for H\&E staining revealed the presence of cells with lacunar space, suggestive of chondroid cells (A. 200x), which was confirmed by Alcian blue staining (B. 200x) and anti-collagen type II staining (C. 200X). In addition, the metastatic tumor was examined by staining for neuro-ectodermal cell lineages markers, including nestin, Blll-tublin and GFAP (D. 400X). Fifty ALDH ${ }^{+} / \mathrm{GD}^{+}$cells sorted from the BC-P007 xenografted tumor were engrafted and the tumor was removed on Day 61(E). H\&E staining revealed the presence of neuron-like cells (circles) (F. 200X). The tumor was examined for the expression of collagen type II, nestin, BIII-tublin and GFAP by immunohistochemical staining. The right upper region expressed anti-human collagen type II (G. 200X), and the left upper region expressed nestin moderate staining, Blll-tublin and GFAP expressed weak staining (H. 400X).

stained positively for collagen type II (Figure 5F) and the left portion contained neuron-like cells by H\&E staining (Figure 5G) with weak to moderate staining for nestin (70\%), $\beta$ III-tublin (10\%) and GFAP (60\%, Figure 5H). In addition, clinical tumor specimens of patients BC007, BC107, BC515 and BC877 were also found to express nestin (approximately 20 to 80\%), BIII-tublin (approximately $<10$ to $35 \%$ ) and approximately GFAP (35 to $80 \%$ ) (Additional file 1: Table S8). Thus, this in vivo system lends further support that $\mathrm{ALDH}^{+}$and $\mathrm{ALDH}^{+} / \mathrm{GD}^{+}$ subpopulations of malignant PTs might be enriched in cells displaying characteristics of MSC, namely the ability for self-renewal and differentiation into a variety of cell lineages including neural specification. To date, this is the first time that malignant PTs were shown to differentiate into neural lineage in vivo.

\section{Discussion}

PTs were derived from the periductal stromal cells of the breast. Malignant stromal transformation in PT is usually of the fibrosarcomatous type [6,7]. Thus, PT lacks cytokeratins which are found in most carcinomas, carcinoid tumors and epithelial organs, but expresses vimentin which is found in tumors of mesenchymal origin, not carcinomas $[24,30]$. In line with this, for all PT samples in our study, their xenografted tumors displayed positive staining for vimentin and negative for cytokeratins. In addition to the common malignant 
fibrous elements, features of rhabdomyosarcoma, liposarcoma and osteosarcoma were occasionally observed in malignant PTs. The heterogeneity of malignant PTs has been largely attributed to metaplastic changes of the malignant stromal cells. The versatile properties of malignant PTs suggest that CSCs exist in PT. We demonstrated for the first time that many markers, including CD44, CD29, CD106, CD166, CD90, CD117 and GD2 were expressed in malignant PTs although CD105 was detected in only 1 of 51 PTs. CD105, a type I membrane glycoprotein that is found in endothelial cells, activated macrophages, fibroblasts and smooth muscle cells is a specific and sensitive marker for tumor angiogenesis. Its expression was associated with increased micro-vessel staining and poor prognosis in childhood's acute lymphoblastic leukemia [31], breast carcinoma [32], colorectal carcinoma [33] and so on. However, whether CD105 is expressed in sarcoma or malignant $\mathrm{PT}$ has not been reported until now. Interestingly, Globo H, a carbohydrate antigen commonly expressed in breast cancer (61 to 80\%), was also detected in malignant PT specimens, albeit at lower frequency (9.8\%). Moreover, several groups have shown an association of the degree of malignancy of PTs with the expressions of Ki-67, CD117, CD10 and p53. Consistent with these reports, high frequency of malignant PTs expressing Ki67 (82.3\%), CD117 (70.5\%), CD10 (60.7\%) and P53 $(50.9 \%)$ was observed in the present study. Furthermore, expression of CD117 (c-kit) was found to correlate significantly with both grades and recurrence of PTs [34]. Since c-kit-overexpressing cancers, including gastrointestinal stromal tumors, could be treated with tyrosine kinase inhibitor, such as imatinib mesylate, it will be of interest to investigate whether malignant PTs may be responsive to c-kit inhibitors.

CSCs play a significant role in the survival and progression of malignant neoplasms [35]. CD $44^{+} / \mathrm{CD} 24^{-}$ have been identified as cancer stem cell markers for breast cancer [36], CD133 ${ }^{+}$aimed at brain tumors [37] and colon cancer [38], as well as CD20 designed for melanoma [39]. More recently, $\mathrm{CD} 45^{-} / \mathrm{CD}^{+} 0^{+}, \mathrm{CD}_{133}{ }^{+}$and $\mathrm{CD} 44^{+}$have been identified as CSC markers for hepatoma [40] osteosarcoma [41] and stomach cancer [42], respectively. However, CSC markers for PT have remained an enigma. In this study, we demonstrated for the first time that $\mathrm{ALDH}^{+}$cells could serve as a marker for enrichment of cancer stem cells in malignant PTs. Moreover, $\mathrm{ALDH}^{+} / \mathrm{GD}^{+}$cells could further enrich CSCs by 33-fold of $\mathrm{ALDH}^{+}$cells based on in vivo tumorigenic potentials. In addition to self-renewal, CSCs harbors the capacity for differentiation into heterogeneous cell lineages. Indeed, tumors engrafted from $\mathrm{ALDH}^{+}$or $\mathrm{ALDH}^{+} / \mathrm{GD}^{+}$cells showed evidence of in vivo differentiation into chondrocytes and neural cells. Furthermore, $\mathrm{ALDH}^{+} / \mathrm{GD}^{+}$cells could be induced to differentiate into adipocytes, osteocytes and chondrocytes as well as neural lineages in vitro. Our observation of neural differentiation of clinical specimens of PTs and their xenografts provided the first evidence for neural differentiation of malignant PTs. Taken together, these data support the notion that ALDH and GD2 may serve as markers for enrichment of CSCs for malignant PTs. It is noteworthy that GD2 has recently been reported to be a marker for CSCs in adenocarcinoma of the breast [11]. The findings of GD2 as a CSC marker for PT and breast cancer have important therapeutic implication, in light of the recent success of anti-GD2 in the treatment of high risk neuroblastoma [43].

\section{Conclusions}

In this study, analysis of 51 clinical specimens of malignant PTs documented the expression of many markers expressed by mesenchymal stem cells, as well as ALDH and Oct-4. Using four xenografts established from primary human PTs, we demonstrated for the first time that ALDH and GD2 could serve as novel markers for malignant PTs, and could enrich CSCs of PTs. Moreover, we provided the first evidence that the sorted $\mathrm{ALDH}^{+} / \mathrm{GD}^{+}$ cells could be induced to differentiate into neural cells of various lineages, in addition to adipocytes, osteocytes and chondrocytes. Evidence of neural differentiation was also observed in clinical specimens and xenografts of malignant PTs. Our findings revealed that malignant PTs possess many characteristics of MSC, and ALDH and GD2 could enrich PT stem cells.

\section{Additional file}

Additional file 1: Table S1. Expression of various markers in tumor and non-tumor parts of PTs obtained from patients and their xenografted tumors in mice by immunohistochemical analysis. Table S2. Expression of vimentin and cytokeratin in tumor and non-tumor parts of PTs obtained from patients and their xenografted tumors by immunohistochemical analysis. Table S3. Colony forming assays of BC-P007 and BC-P515. Table S4. A comparison of mammosphere formation efficiency (MEF) of $\mathrm{ALDH}^{+}$ and $\mathrm{ALDH}^{-}$subpopulations. Table S5. Engraftment of tumors in NOD/SCID mice with different cell populations sorted from monolayer cultured cells, mammospheres and cryopreserved xenografted cells of BC-P007. Table S6. Comparison of the in vitro/in vivo growth properties and differentiation capacity of cells harvested from the tumor and non-tumor parts of malignant PT, BC-P515. Table S7. $\mathrm{ALDH}^{+} / \mathrm{GD}^{+}$cells could be serially passaged in mice. Table S8. Clinical tumor specimens of patients expressed nestin, BIII-tublin and GFAP. Figure S1. Immunofluorescence analysis of BC-P007 colonies and mammosphere culture.

\section{Abbreviations}

ALDH: Aldehyde dehydrogenase 1; CSCs: Cancer stem cells; GFAP: Glial fibrillary acidic protein; ITS: Insulin-Transferrin-Selenium; MFE: Mammosphere forming efficiency; MSCs: Mesenchymal stem cells; NOD-SCID mice: Nonobese diabetic-severe combined immunodeficient mice; PTs: Phyllodes tumors; TGF- $\beta$ : Transforming growth factor beta.

\section{Competing interests}

The authors indicate no potential conflicts of interest. 


\section{Authors' contributions}

$J J L$ performed most of the experiments, analyzed the data and wrote the paper. JY drafted the manuscript and the experimental design. CSH, GSL, $\mathrm{HCL}$ and KTY collected the specimens, supervised the project and participated in discussions of the study design. JTH and RJL helped with data analysis and interpretation, as well as with manuscript writing. FPC conceived and coordinated the study. KTY and ALY contributed to study conception, experimental design and manuscript writing. All authors have approved the final manuscript for publication and agreed to be accountable for all aspects of the work.

\section{Acknowledgments}

We confirm that this manuscript has not been published elsewhere except that part of the results was presented in abstract form at the 101th American Association for Cancer Research (AACR) annual meeting. We thank the pathologists Drs.Tsung-His Wang, Yih-Yiing Wu and Bey-Leei Ling for their expert consultation on the immunohistochemical analysis of phyllodes tumor samples. We are indebted to Li-Wen LO and Wen-Wen Chen for their service in cell imaging and flow cytometry. This research was supported by Academia Sinica and grants from National Science Council in Taiwan (A.L. Yu, NSC972323-B-001 and NSC 100-2321-B-001-037).

\section{Author details}

'Genomics Research Center, Academia Sinica, 128 Academia Road, Section 2, Taipei 11529, Taiwan. ${ }^{2}$ Institute of Biochemistry and Biotechnology, College of Medicine, Chung Shan Medical University, Taichung, Taiwan. ${ }^{3}$ Department of Surgery, College of Medicine, National Taiwan University, Taipei, Taiwan. ${ }^{4}$ Department of Surgery, Division of General Surgery, Tri-Service General Hospital, Taipei, Taiwan. ${ }^{5}$ Department of Pathology, College of Medicine, National Taiwan University, Taipei, Taiwan. ${ }^{6}$ Institute of Stem Cell \& Translational Cancer Research, Chang Gung Memorial Hospital at Linkou, Taoyuan, Taiwan. ${ }^{7}$ Department of Surgical Pathology, Changhua Christian Hospital, Changhua 135, Nansiao St, Changhua 500, Taiwan.

Received: 18 June 2013 Accepted: 10 March 2014

Published: 26 March 2014

\section{References}

1. Karim RZ, Scolyer RA, Tse GM, Tan PH, Putti TC, Lee CS: Pathogenic mechanisms in the initiation and progression of mammary phyllodes tumours. Pathology 2009, 41:105-117.

2. Coronel-Brizio PG, Quistian Navarrete F, Guzman Garcia RE, Zoloeta Dominguez PA, Venegas Espinosa B: Primary sarcoma of the mammary gland. Ginecol Obstet Mex 2012, 80:777-782.

3. Tan PH, Jayabaskar T, Chuah KL, Lee HY, Tan Y, Hilmy M, Hung H, Selvarajan S, Bay BH: Phyllodes tumors of the breast: the role of pathologic parameters. Am J Clin Pathol 2005, 123:529-540.

4. Tsai WC, Jin JS, Yu JC, Sheu LF: CD10, actin, and vimentin expression in breast phyllodes tumors correlates with tumor grades of the WHO grading system. Int I Surg Pathol 2006, 14:127-131.

5. Bernardi G, Cavallaro G, Indinnimeo M, Fiore A, Basso L, D'Ermo G, De Toma $G$, Cavallaro A: Usefulness of ultrasounds in the management of breast phyllodes tumors. II Giornale di chirurgia 2012, 33:81-85.

6. Bilen MA, Laucirica R, Rimawi MF, Nangia JR, Cyprus GS: Jejunal intussusception due to malignant phyllodes tumor of the breast. Clin Breast Cancer 2012, 12:219-221.

7. Hemalatha AL, Sindhuram VS, Asha U: MFH Mimic in breast: a high-grade malignant phyllodes tumor. Case Reports Pathol 2012, 2012:835687.

8. Friedenstein AJ, Deriglasova UF, Kulagina NN, Panasuk AF, Rudakowa SF, Luria EA, Ruadkow IA: Precursors for fibroblasts in different populations of hematopoietic cells as detected by the in vitro colony assay method. Exp Hematol 1974, 2:83-92.

9. Bae KS, Park JB, Kim HS, Kim DS, Park DJ, Kang SJ: Neuron-like differentiation of bone marrow-derived mesenchymal stem cells. Yonsei Med J 2011, 52:401-412.

10. Martinez C, Hofmann TJ, Marino R, Dominici M, Horwitz EM: Human bone marrow mesenchymal stromal cells express the neural ganglioside GD2: a novel surface marker for the identification of MSCs. Blood 2007, 109:4245-4248.

11. Battula VL, Shi Y, Evans KW, Wang RY, Spaeth EL, Jacamo RO, Guerra R, Sahin AA, Marini FC, Hortobagyi G, Mani SA, Andreeff M: Ganglioside GD2 identifies breast cancer stem cells and promotes tumorigenesis. J Clin Invest 2012, 122:2066-2078.

12. Quintana E, Shackleton M, Sabel MS, Fullen DR, Johnson TM, Morrison SJ: Efficient tumour formation by single human melanoma cells. Nature 2008, 456:593-598.

13. Kuperwasser C, Chavarria T, Wu M, Magrane G, Gray JW, Carey L, Richardson A, Weinberg RA: Reconstruction of functionally normal and malignant human breast tissues in mice. Proc Natl Acad Sci U S A 2004, 101:4966-4971.

14. Chang WW, Lee CH, Lee P, Lin J, Hsu CW, Hung JT, Lin JJ, Yu JC, Shao LE, Yu J, Wong $\mathrm{CH}$, YU AL: Expression of Globo $\mathrm{H}$ and SSEA3 in breast cancer stem cells and the involvement of fucosyl transferases 1 and 2 in Globo H synthesis. Proc Natl Acad Sci U S A 2008, 105:11667-11672.

15. Chute JP, Muramoto GG, Whitesides J, Colvin M, Safi R, Chao NJ, McDonnell DP: Inhibition of aldehyde dehydrogenase and retinoid signaling induces the expansion of human hematopoietic stem cells. Proc Natl Acad Sci U S A 2006, 103:11707-11712.

16. Dialynas DP, Lee MJ, Gold DP, Shao L, Yu AL, Borowitz MJ, Yu J: Preconditioning with fetal cord blood facilitates engraftment of primary childhood T-cell acute lymphoblastic leukemia in immunodeficient mice. Blood 2001, 97:3218-3225.

17. Conget PA, Minguell JJ: Phenotypical and functional properties of human bone marrow mesenchymal progenitor cells. J Cell Physiol 1999, 181:67-73.

18. Pittenger MF, Mackay AM, Beck SC, Jaiswal RK, Douglas R, Mosca JD, Moorman MA, Simonetti DW, Craig S, Marshak DR: Multilineage potential of adult human mesenchymal stem cells. Science 1999, 284:143-147.

19. in't Anker PS, Noort WA, Scherjon SA, Kleijburg-van der Keur C, Kruisselbrink AB, van Bezooijen RL, Beekhuizen W, Willemze R, Kanhai HH, Fibbe WE: Mesenchymal stem cells in human second-trimester bone marrow, liver, lung, and spleen exhibit a similar immunophenotype but a heterogeneous multilineage differentiation potential. Haematologica 2003, 88:845-852.

20. Fan CG, Tang FW, Zhang QJ, Lu SH, Liu HY, Zhao ZM, Liu B, Han ZB, Han ZC: Characterization and neural differentiation of fetal lung mesenchymal stem cells. Cell Transplant 2005, 14:311-321.

21. Deng W, St Hilaire RC, Chattergoon NN, Jeter JR Jr, Kadowitz PJ: Inhibition of vascular smooth muscle cell proliferation in vitro by genetically engineered marrow stromal cells secreting calcitonin gene-related peptide. Life Sci 2006, 78:1830-1838.

22. Kaçar A, Paker I, Akbiyik F, Arikök AT, Mambet E: CD117 and CD34 staining patterns in childhood benign mammary lesions. Turk Patoloji Derg 2012, 28:31-37.

23. Hung T, Crawford RI: Trichoblastic sarcoma with osteosarcomatous differentiation: evolution of one lesion with 3 histologic appearances over a 3-year period. Am J Dermatopathol 2012, 34:658-662.

24. Fujii T, Shimada K, Tanaka N, Fujimoto K, Konishi N: Phyllodes tumor of the prostate. Pathol Int 2012, 62:204-208.

25. Dal Vechio AM, Giudice FS, Sperandio FF, Mantesso A, Pinto Junior Ddos S: Vimentin expression and the influence of Matrigel in cell lines of head and neck squamous cell carcinoma. Braz Oral Res 2011, 25:235-240.

26. Esposito NN, Mohan D, Brufsky A, Lin Y, Kapali M, Dabbs DJ: Phyllodes tumor: a clinicopathologic and immunohistochemical study of 30 cases. Arch Pathol Lab Med 2006, 130:1516-1521.

27. Liu J, Liu YH: [Expression of CD117, CD34, SMA, S-100 protein, Vim and desmin in patients with gastrointestinal stromal tumors]. Nan Fang Yi Ke Da Xue Xue Bao 2008, 28:438-440.

28. Zhang S, Cordon-Cardo C, Zhang HS, Reuter VE, Adluri S, Hamilton WB, Lloyd KO, Livingston PO: Selection of tumor antigens as targets for immune attack using immunohistochemistry: I. Focus on gangliosides. Int J Cancer 1997, 73:42-49.

29. Ginestier C, Hur MH, Charafe-Jauffret E, Monville F, Dutcher J, Brown M, Jacquemier J, Viens P, Kleer CG, Liu S, Schott A, Hayes D, Birnbaum D, Wicha MS, Dontu G: ALDH1 is a marker of normal and malignant human mammary stem cells and a predictor of poor clinical outcome. Cell Stem Cell 2007, 1:555-567.

30. Chia Y, Thike AA, Cheok PY, Yong-Zheng Chong L, Man-Kit Tse G, Tan PH: Stromal keratin expression in phyllodes tumours of the breast: a comparison with other spindle cell breast lesions. J Clin Pathol 2012 65:339-347.

31. Catchpoole D, Lail A, Guo D, Chen QR, Khan J: Gene expression profiles that segregate patients with childhood acute lymphoblastic leukaemia: an independent validation study identifies that endoglin associates with patient outcome. Leukemia Res 2007, 31:1741-1747. 
32. Dales JP, Garcia S, Bonnier P, Duffaud F, Andrac-Meyer L, Ramuz O, Lavaut MN, Allasia C, Charpin C: CD105 expression is a marker of high metastatic risk and poor outcome in breast carcinomas. Correlations between immunohistochemical analysis and long-term follow-up in a series of 929 patients. Am J Clin Pathol 2003, 119:374-380.

33. Saad RS, Liu YL, Nathan G, Celebrezze J, Medich D, Silverman JF: Endoglin (CD105) and vascular endothelial growth factor as prognostic markers in colorectal cancer. Mod Pathol 2004, 17:197-203.

34. Tan PH, Jayabaskar T, Yip G, Tan Y, Hilmy M, Selvarajan S, Bay BH: p53 and c-kit (CD117) protein expression as prognostic indicators in breast phyllodes tumors: a tissue microarray study. Mod Pathol 2005, 18:1527-1534.

35. Adams JM, Kelly PN, Dakic A, Carotta S, Nutt SL, Strasser A: Role of "cancer stem cells" and cell survival in tumor development and maintenance. Cold Spring Harb Symp Quant Biol 2008, 73:451-459.

36. Farnie G, Clarke RB: Mammary stem cells and breast cancer-role of Notch signalling. Stem Cell Rev 2007, 3:169-175.

37. Singh SK, Hawkins C, Clarke ID, Squire JA, Bayani J, Hide T, Henkelman RM, Cusimano MD, Dirks PB: Identification of human brain tumour initiating cells. Nature 2004, 432:396-401.

38. O'Brien CA, Pollett A, Gallinger S, Dick JE: A human colon cancer cell capable of initiating tumour growth in immunodeficient mice. Nature 2007, 445:106-110.

39. Fang D, Nguyen TK, Leishear K, Finko R, Kulp AN, Hotz S, Van Belle PA, Xu X, Elder DE, Herlyn M: A tumorigenic subpopulation with stem cell properties in melanomas. Cancer Res 2005, 65:9328-9337.

40. Salnikov AV, Kusumawidjaja G, Rausch V, Bruns H, Gross W, Khamidjanov A, Ryschich E, Gebhard MM, Moldenhauer G, Büchler MW, Schemmer P, Herr I: Cancer stem cell marker expression in hepatocellular carcinoma and liver metastases is not sufficient as single prognostic parameter. Cancer Lett. 2009, 275:185-93

41. Tirino V, Desiderio V, d'Aquino R, De Francesco F, Pirozzi G, Graziano A, Galderisi U, Cavaliere C, De Rosa A, Papaccio G, Giordano A: Detection and characterization of $\mathrm{CD} 133+$ cancer stem cells in human solid tumours. PLoS One 2008, 3:e3469.

42. Takaishi S, Okumura T, Tu S, Wang SS, Shibata W, Vigneshwaran R, Gordon SA, Shimada Y, Wang TC: Identification of gastric cancer stem cells using the cell surface marker CD44. Stem Cells 2009, 27:1006-1020.

43. Yu AL, Gilman AL, Ozkaynak MF, London WB, Kreissman SG, Chen HX, Smith M, Anderson B, Villablanca JG, Matthay KK, Shimada H, Grupp SA, Seeger R, Reynolds CP, Buxton A, Reisfeld RA, Gillies SD, Cohn SL, Maris JM, Sondel PM, Children's Oncology Group: Anti-GD2 antibody with GM-CSF, interleukin-2, and isotretinoin for neuroblastoma. N Engl J Med 2010, 363:1324-1334.

\section{doi:10.1186/bcr3631}

Cite this article as: Lin et al:: Malignant phyllodes tumors display mesenchymal stem cell features and aldehyde dehydrogenase/ disialoganglioside identify their tumor stem cells. Breast Cancer Research 2014 16:R29.

\section{Submit your next manuscript to BioMed Central and take full advantage of:}

- Convenient online submission

- Thorough peer review

- No space constraints or color figure charges

- Immediate publication on acceptance

- Inclusion in PubMed, CAS, Scopus and Google Scholar

- Research which is freely available for redistribution 